tion in the conditions of medical education in London if the metropolis is to maintain its leading position.

Recommendations of the Faculty.

"An examination of the expression of opinion from the schools shows that although there is not a complete consensus of opinion in regard to the mode in which concentration should be carried out, there is nevertheless a very strong desire on the part of the majority of the schools to see the principle of concentration applied.

"Further, it appears that the opinion in favour of concentration is gaining ground, and it is believed that decisive action en the part of the University authorities in the direction now recommended will remove so much of the remaining opposition as is due to the not unnatural fear of some of the schools lest a method of concentration should be adopted which would benefit one or more institutions to the detriment of others.

"The Faculty recommends that the Senate should take steps to secure funds to enable it to establish in the near neighbourhood of the University a school of preliminary and intermediate medical studies.

"'The Faculty has no doubt of the immediate success of such a school, and of its good influence upon medical education throughout the metropolis, provided that the following requirements are met:

(a) That the funds forthcoming are sufficient to provide ample educa tional facilities, and adequate remuneration for the teachers, withou increasing the present cost of education to the students.

(b) That provision is made for teaching all classes of medical students whether preparing for the examinations of the University or for those other qualifying bodies, so that any existing school of the Universit should be able at once to abandon altogether the teaching of the subjects provided for at the new school

(c) That due provision is made for research.

(d) That adequate provision is made for the instruction of women students in an institution under the direct control of the University

"When such a policy is within measurable distance of fulfilment, the Faculty believes that the Senate will have little difficulty in coming to satisfactory arrangements with the schools of the University to transfer a large number of students to the Central School in addition to those who would be directly attracted thereto.

"With regard to those schools which desire to retain the teaching of the preliminary and intermediate subjects, it seems to the Faculty. that they should be permitted to do so subject to the approval of the Senate that their courses of study are suitable for internal students. In this way the objections which have been felt by some of the schools to concentration at a single centre might be met.

"The University will thus be able not only to improve the teaching of the subjects which it will directly provide for, but it will also enable those schools which relinquish the teaching of these subjects to make necessary and important advances in teaching and in research in those branches of study which they will still retain."

\section{THE PLAGUE.}

\section{Prevalence of the Disease.} INDIA.

THE plague mortality for the weeks ending November gth, 16th, and ${ }_{23}$ rd for all India were $8.990,8.710$, and $8,43 \mathrm{r}$ respectively. The numbers of plague deaths have remained at over 8,000 since the week ending October 12th, and although the numbers show some signs of decreasing, the retrocession is but slow.

In the city of Bombay the number of plague deaths during the week ending November 9 th, 16 th, and 23 rd were $172,18 \mathrm{r}$, and 177 respectively. Althongh there has been a slight decline in the mortality from plague, there has been a corresponding increase in the number of deaths from respiratory diseases and dysentery.

At, a plague rolunteer meeting held at Poona on Tuesday, November 26th, General Burnett, who presided, said that there were only two ways of minimising the evil effects of the plague epidemic. namely, inoculation and evacuation. From the statistics it appeared that there had been in Poona only 34 deaths among the inoculated since the year r897. Four thousand persons had heen inoculated during the present year, and almost 20,000 last year. Within the past few days (November 26th) 2,000 persons from Poona had gone into tents on the advice of the authorities, who urgently recommended evacuation of plague-infec!ed

In Calcutta the number of plague deaths was 35 during the week enjing November oth

In Karachi during the week ending November 16 th the number of fresh cases was 84 and 50 deaths from the disease.
In Poona from 25 to 35 fresh cases of plague were reported daily during the third week of November.

In Satara the outbreak threatens to become serious; between October 2yth and November 17 th, 259 fresh cases of plague occurred and 193 deaths from the disease.

C'APE OF GOOD HOPE.

In the Cape Peninsula no fresh cases of plague were recorded during either of the weeks ending Novenber 3 oth and December 7 th, nor were there any deaths from the disease.

At Port Elizabeth during the weeks ending November 3 oth and December 7 th the fresh cases of plague were 2 and 1 respectively, and core clize cher Dever 3 th, and Decem occur At roding Capetown, 2 cases supposed to be plague were reported during the firs were reported during the week ending December 7 th. EGYPT.

During the week ending December ist, 2 cases of plague and 3 death from the disease were reported by the Director-General of the Sanitary Department as having occurred throughout Egypt. All the cases and deaths occurred among natives at Zifteh. During the week ending November 24th a man was found dead out of hospital at Zifteh, and on examination the cause of death was proved to be pneumonic plague. A few days subsequently (November 27th) the man's wife and, later, his mother-in-law were taken ill and both died of pneumonic plagie. It is direct infection of pneumonic plague seems to be undoubted, whatever may be said of bubonic plague.

During the week ending Deceuritius. During the week ending December 5 th, $5^{2}$ cases of plague occurred in

\section{THE LATE R. B. ANDERSON FUND.}

Wr have received the following letter as we go to press:

Sir,-Permit me to add a word to the appeal of Lord Stamford and $\mathrm{Mr}$. Timothy Holmes in reference to the R. B. Anderson Fund. It seems a most melancholy and depressing thought that an appeal renewed at intervals over six months, made by men of the highest standing, backed up by the editors of the great medical journals, and on behalf of a man who was one of the martyrs of the profession, if ever we had one, should only result in the miserable sum of $£ 80$. This is both inadequate for the pressing needs of Mrs. Anderson and family and discreditable to the profession.

When Mr. Anderson was alive-when the memory of the gross injustice perpetrated on him (and through him on the profession) was fresh-we rewarded him for his heroic endeavours to secure justice in the usual way. He was looked on as a crank, a misguided enthusiast, a man with a grievance, and therefore a nuisance. Or even worse, he was regarded with suspicion and his motives impugned. Ridiculous as it will seem to those who knew him I have even met people who talked of him as a "paid agitator"! The last few years of his life were spent in anxiety and poverty. I am afraid that sometimes he even had not enough to eat. It is a story that we as a profession can only recall with shame; but it is not too late to do something for our credit's sake.

Especially would I appeal to those who take an interest in medical politics. I had the honour of Mr. Anderson's intimate acquaintance, and never did I meet a man to whom the honour and interests of the profession were so sacred. Even his own wrongs were swallowed up in his enthusiasm for the cause. When the rights of the profession were assailed in his person he defended them with a courage and tenacity which nothing could shake. He faced prison and financial ruin rather than compromise one jot of those rights. He hastened his own death by the privations and mental anxiety incurred in fighting a battle which was not his alone but that of the whole profession. We may think his conduct quixotic, and that he was foolish in neglecting his family and financial interests in order to fight the battle. But those of us who would have been less courageous (more prudent, if you will), may at any rate honour his undaunted spirit, and sympathise with the family left in very distressed circumstances. Every man who reads this could afford a few shillings, and I trust, for the honour of the profession, that the fund will not be closed in anything like its present miserable state.

I shall personally be glad to receive and forward to the Treasurer, any subscriptions sent to me.-I am, etc. Cotfield House, Gateshead, Dec. 18th. 